\title{
The Market for Nanotechnology Applications and Its Managerial Implications: An Empirical Investigation in the Italian Landscape
}

\author{
Lucio Cassia and Alfredo De Massis \\ University of Bergamo \\ Italy
}

\section{Introduction}

In the last 7 to 8 years attention towards nanotechnology and its applications has greatly increased, both in academic and industrial environments. Its potential was recognised earlier in the 1959 speech by Nobel Laureate Richard Feynman, 'There's Plenty of Room at the Bottom', at the annual meeting of the American Physical Society at the California Institute of Technology (Caltech). The great expectations that surround nanotechnology are witnessed by the growth of public funds devoted to research into the field. In 2004, these funds reached the amount of approximately 4.6 billion US Dollars worldwide, with an increase of more than 700\% with respect to 1997 (www.luxresearchinc.com, 2004). Several European countries started national nanotechnology research programs between the mid1980 's and mid-1990's. Here the overall investment of around 200 million Euro in 1997 has risen to approximately 1,000 million Euro in 2003 (www.nanoinvestors.com, 2004). Moreover, nanotechnology was identified as a main priority area in the 6th Framework Programme ( $250 \mathrm{M} €$ /year). Italy, with over 1,200 people directly involved and 70 million Euro of R\&D funding, is shaping up to be a major world player in nanotechnology. Here significant nanotech investment have been realised, both in private and public sectors, and dedicated research centres have been established (www.nanotec.it, 2004).

Today, a market for nanotechnology's applications is therefore emerging. Even if still limited in dimensions, its value is approximately of 50-60 million U.S Dollars (European Commission, 2004a, b), but is thought by analysts to be capable of rising to hundreds of billion sale volumes by 2010, and exceeding one trillion after (www.nanobusiness.org, 2000). However, the novelty of the nanotech market, the pervasiveness of nanotechnologies and the complexity of their applications, the lack of common definitions, concepts and market boundaries, make it very difficult to clearly distinguish between nanotech and non-nanotech companies.

In this paper, building on previous research on nanotechnology firms classification (Chiesa \& De Massis, 2006), we label as 'nanotech' a company that: (i) carries out R\&D activities on nanotechnology (devoting human, technological and financial resources to its study); (ii) can be easily arranged in one or more of the four "nanotechnology categories" (nanomaterials, nanotools, nanostructures, and nanoprocesses) considered in the framework developed by Chiesa et al. (2005a). 
The objectives of this paper are twofold:

- to offer a picture of the overall Italian market for nanotech applications, i.e. to identify the main Italian players operating in the nanotechnology and to collect the data and information needed in order to understand the general characteristics if this market (companies' dimension, geographical location, industry, main activities, and nanotechnology category(ies) in which they operate); and,

- to provide, through the analysis of some relevant variables, a description of the management and organisation of the players operating in such a market, drawing out the emerging business models and understanding the determinants of these configurations in light of the specific characteristics of the different players and the nanotechnology categories in which they operate.

Given these objectives, this paper deliberately does not consider either the academic/public research organisations or the private research centres involved in nanotechnology, but is focused solely on Italian private industrial nanotech companies which operate in order to commercialise nanotech applications.

The paper is structured as follows: Section 2 describes the research methodology; Section 3 illustrates the empirical study and discusses the empirical results; finally, Section 4 draws some conclusions, considers the implications for academics and practitioners, and suggests future directions of research.

\section{Research methodology}

As previously pointed out, the paper has two main objectives:

The first objective is to describe the Italian market for nanotech applications, i.e. to identify its main players and collect some general information useful for understanding the market as a whole, such as: (i) the companies' dimensions; (ii) the localisation; (iii) the main activities undertaken. As far as this objective is concerned, an extensive analysis was conducted and focused on the following topics: (i) diffusion of nanotech firms; (ii) aspects related with the localisation of these companies; (iii) type of activities conducted and nanotechnology categories where they work. The main problems in organising the extensive analysis were related to the novelty of the nanotech market, the pervasiveness of nanotechnologies and the complexity of their applications, the lack of common definitions, concepts and market boundaries. Considering these difficulties, it was decided to base the research on the web, searching for the websites of companies that develop, produce and/or use nanotech products or processes. The main limitations associated with the use of Internet as research tool are related to the generally low validity of the information collected (Hewson et al., 2003). This is mainly due to the: (i) subjectivity introduced by the researcher which, on the basis of his personal characteristics, is led to select some information rather than others; (ii) lack of controls over the material published on the web. However, such limitations can be easily overcome by considering that: (i) the extensive analysis needs general and objective information, mostly descriptive in nature and publicly available, which are usually well suited to accurate and precise publication on the web; (ii) the great attention from information-providers directed towards those few Italian companies operating in nanotechnology has led to a wide diffusion of information on the web about such companies, thus giving the opportunity to validate their reliability through the comparison of different online sources of information. The data collected were then integrated with reports drawn from various sources (www.luxresearchinc.com, 2004; www.nanoinvestornews.com, 2004; 
European Commission, 2004a; www.investinitaly.com, 2004; www.nanovip.com, 2004; www.nanotec.it, 2004; Nanotech/It, 2004; Caravita, 2004a, b).

The second objective of the paper is to provide a description of the management and organisational practices adopted by Italian nanotech players, investigating the emerging business models. According to this objective, it was decided to conduct an intensive analysis based on a multiple case study aimed at in-depth analysing the previously identified sample of Italian nanotech companies. It is worth mentioning that multiple case study research appears here to fit with the objective of the analysis (Yin, 2003; Eisenhardt, 1989) since the investigated phenomenon is very complex and hardly distinguishable from its context (i.e. the competitive environment in which firms operate), and the investigation of the business models requires to explore processes and activities and answering "how" and "why" questions, providing explanations rather than statistical information. Only 14 of the 19 identified nanotech companies (74\% of the population) gave their availability to cooperate in the research.

Two semi-structured telephone or personal interviews were conducted with all the top - or research - managers of the 14 companies between the end of 2004 and the first half of 2005, through a questionnaire specifically designed in order to analyse the business models of the companies. Given that many authors have offered definitions of the term 'business model' (see Chesbrough \& Rosenbloom, 2002), but no generally accepted definition of a business model has emerged to date (Shafer et al., 2005), the business model as used in this study is the set of answers to the following five questions (Hellström \& Sjölander, 2005): (i) What is the offer to the customer? (ii) Who is the customer? (iii) What is the value thereby created for the customer? (iv) How can the firm appropriate a sufficient share of that value? (v) How is that offer conveyed to the customer? Have been therefore explored variables related to: (i) the nanotech output and the characteristics of the customers to which it is offered (type of output, method of use of nanotechnology, type of served market, destination of the output in terms of industries of origin of the main customers); (ii) the mechanism adopted by the company for entering the nanotech business and the degree of correlation between the core and the nanotech business; (iii) the way the company manages the sale of nanotech output (marketing approach, model of involvement of the client company, degree of standardisation/ customisation of the provided output, phase(s) of interaction with the client company, commercial relationship management model); (iv) the structure adopted in order to organise the technical personnel and the relating activities; $(\mathrm{v})$ the intellectual property management model and the strategies used for solving the appropriation problems.

The interviews were integrated with internal and public documentations (newspaper articles, websites, balance sheets) and archival records (list of products, organisational charts, service records), thus allowing the triangulation of empirical evidence (Patton, 1987).

\section{The empirical study}

The empirical study has been divided into two distinct parts:

- the extensive analysis;

- the intensive analysis.

\subsection{The extensive analysis: basic results}

According to the definition of 'nanotech company' adopted in this study, 19 firms were identified in the Italian landscape. They are listed in Table 1, together with their location and industry of origin. 


\begin{tabular}{|c|c|c|}
\hline Company & Location & Industry \\
\hline APE Researech & Basovizza (TS) & Instrumentation \\
\hline CRF (Centro Ricerche Fiat) & Torino & Automotive \\
\hline CSM & Roma & Materials \\
\hline EniTecnologie & San Donato Milanese (MI) & Energy \\
\hline Geal & Agliana (PT) & Chemicals \\
\hline Kedrion & Castelvecchio Pascoli-Barga (PT) & Pharmaceuticals \\
\hline MBN & San Vendemiano (TV) & Materials \\
\hline Microcoat & Sedriano (MI) & Coatings \\
\hline Moma & Reggiolo (RE) & Coatings \\
\hline Olivetti I-Jet & Arnad (AO) & Microelectronics \\
\hline Organic Spintronics & Bologna & Materials \\
\hline Pirelli Labs & Milano & Information Technology \\
\hline Pometon & Maerne di Martellago (VE) & Materials \\
\hline SAES Getters & Lainate (MI) & Instrumentation \\
\hline Scriba Nanotecnologie & Bologna & Materials \\
\hline SIAD & Bergamo & Chemicals \\
\hline Sorin Biomedica Cardio & Saluggia (VC) & Biomedicine \\
\hline STMicroelectronics & Agrate Brianza (MI) & Microelectronics \\
\hline Tethis & Milano & Coatings \\
\hline
\end{tabular}

Table 1. Italian nanotech companies.

First, it is therefore possible to observe the low number of players compared to other countries (e.g. U.S., Germany, France and Japan), in confirmation of the embryonic of stage of the Italian market for nanotech applications.

The nanotech companies are mostly located in the northern part of the country (15 firms, corresponding to $84 \%$ of the sample); three of them (16\% of the sample) are located in the central part of Italy. No companies have been found in the South or in the islands. The geographical distribution of nanotech companies is shown in Figure 1.

Interesting findings emerge when the industries in which the nanotech companies operate are analysed. These are summarized in Table 2.

\begin{tabular}{|c|c|}
\hline Industry & Number (\%) of companies operating in the industry \\
\hline Materials & $5(26)$ \\
\hline Coatings & $3(16)$ \\
\hline Microelectronics \& ICT & $3(16)$ \\
\hline Chemicals & $2(11)$ \\
\hline Instrumentation & $2(11)$ \\
\hline Energy & $1(5)$ \\
\hline Pharmaceuticals & $1(5)$ \\
\hline Biomedicine & $1(5)$ \\
\hline Automotive & $1(5)$ \\
\hline
\end{tabular}

Table 2. Number (and percentage) of Italian nanotech companies operating in different industries 


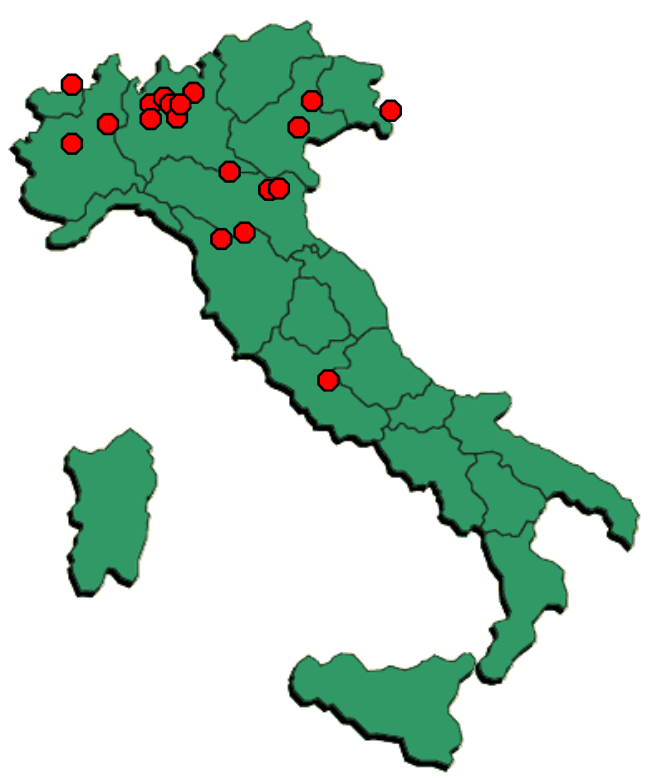

Fig. 1. Geographical distribution of Italian nanotech companies.

It becomes clear that in Italy nanotechnologies are mainly applied in the development and production of improved materials, which, at the moment, seem to be the most promising nanotech applications. They are also being used in the engineering of enhanced coating treatments and for the realization of microelectronic and ICT devices. Chemicals and instrumentation are other important industrial sectors where nanotech applications are being implied.

In Table 3, the 19 Italian companies are classified into the four nanotechnology categories identified in the nanotechnology categorisation framework proposed by Chiesa et al. (2005a).

\begin{tabular}{|c|c|c|c|}
\hline \multicolumn{4}{|c|}{ Nanotechnology categories } \\
\hline Nanomaterials & Nanotools & Nanostructures & Nanoprocesses \\
\hline CSM & APE Research & CRF & EniTecnologie \\
Geal & & Kedrion & Microcoat \\
MBN & & Olivetti I-Jet & Moma \\
Pometon & & Pirelli Labs & Organic Spintronics \\
SIAD & & Sorin Biomedica Cardio & Scriba Nanotecnologie \\
& & STMicroelectronics & SAES Getters \\
& & & Tethis \\
\hline
\end{tabular}

Table 3. Distribution of Italian nanotech companies in the nanotechnology categories.

It is possible to note that:

- the majority of companies (7, corresponding to $37 \%$ of the sample) use nanotechnologies in order to carry out, for the client firm, specific nanotech processes (e.g. magnetic abrasive finishing, thin film deposition); 
- 6 firms (32\% of the sample) apply nanotech intermediate findings (e.g. nanotubes), instrumentation operating at the nanoscale (e.g. piezodriven nanopositioners) or nanotech processes (e.g. nanolithography) in order to produce and commercialise innovative devices classifiable as nanostructures, i.e. complex systems made of different parts matched together that perform different functions (e.g. the Nano-ElectroMechanical-Systems (NEMS) fabricated by STMicroelectronics);

- 5 companies ( $26 \%$ of the sample) apply nanotechnologies in order to manufacture innovative materials (e.g. nanopowders);

- just one firm (A.P.E. Research) uses nanotechnologies in order to fabricate and sell to client companies high-precision tools operating at the nanoscale (e.g. atomic force microscopes).

Finally, considering the dimensions of the analysed companies, it is possible to identify:

- 7 big companies (STMicroelectronics, SIAD, SAES Getters, Centro Ricerche Fiat-CRF, Sorin Biomedica Cardio, EniTecnologie, Kedrion) that employee $70 \%$ of the overall personnel working in the field;

- 4 medium-sized enterprises (Olivetti I-Jet, CSM, Pometon, Pirelli Labs), with a number of employees between 200 and 344;

- 2 small companies (Geal, MBN), employing 32 and 35 persons respectively;

- 6 micro-firms, with less than 9 employees. They are start-ups (Microcoat, Moma) or academic spin-offs (Tethis, APE Research, Organic Spintronics, Scriba Nanotecnologie) recently founded (the oldest company is APE Research, founded in 1996).

The intensive analysis, the results of which are described in the next session, includes the study of the management and organisational practices adopted by Italian nanotech companies, and the investigation of the interrelations between such practices, the dimension of the companies, and the nanotechnology category in which they work.

\subsection{The intensive analysis: basic results}

The empirical evidence collected during the intensive analysis is schematically reported in Table 4.

The main results of the intensive analysis can be summarised as follows.

- Significantly, it is possible to identify four methods according to which the companies use nanotechnology to obtain the commercialisable output:

M1. the method adopted by nanotech companies developing intermediate findings (e.g. nanopowders) to be sold, licensed out or partnered with the client company, that carries out the remaining tasks of the development process and includes them into its innovative products. These companies provide a service of "Work In Progress (WIP) Innovation" (Chiesa et al., 2005b) and typically operate in the category of nanomaterials;

M2. the method adopted by nanotech companies carrying out, for the client firm, a particular process (e.g. thin film deposition) that requires excellent competencies in a specific scientific domain. These companies provide a service of "Process Activity" (Chiesa et al., 2005b), and usually operate in the nanoprocesses category.

M3. the method adopted by nanotech companies developing and selling instrumentation operating at the nanoscale (e.g. Scanning Probe Microscopes or software for real-time imaging) that is used by the client firm for supporting its innovation processes (typically, its basic and applied research activities). These 
companies provide a service of "Technologies to develop technology" (Debackere, 1999) and typically operate in the category of nanotools;

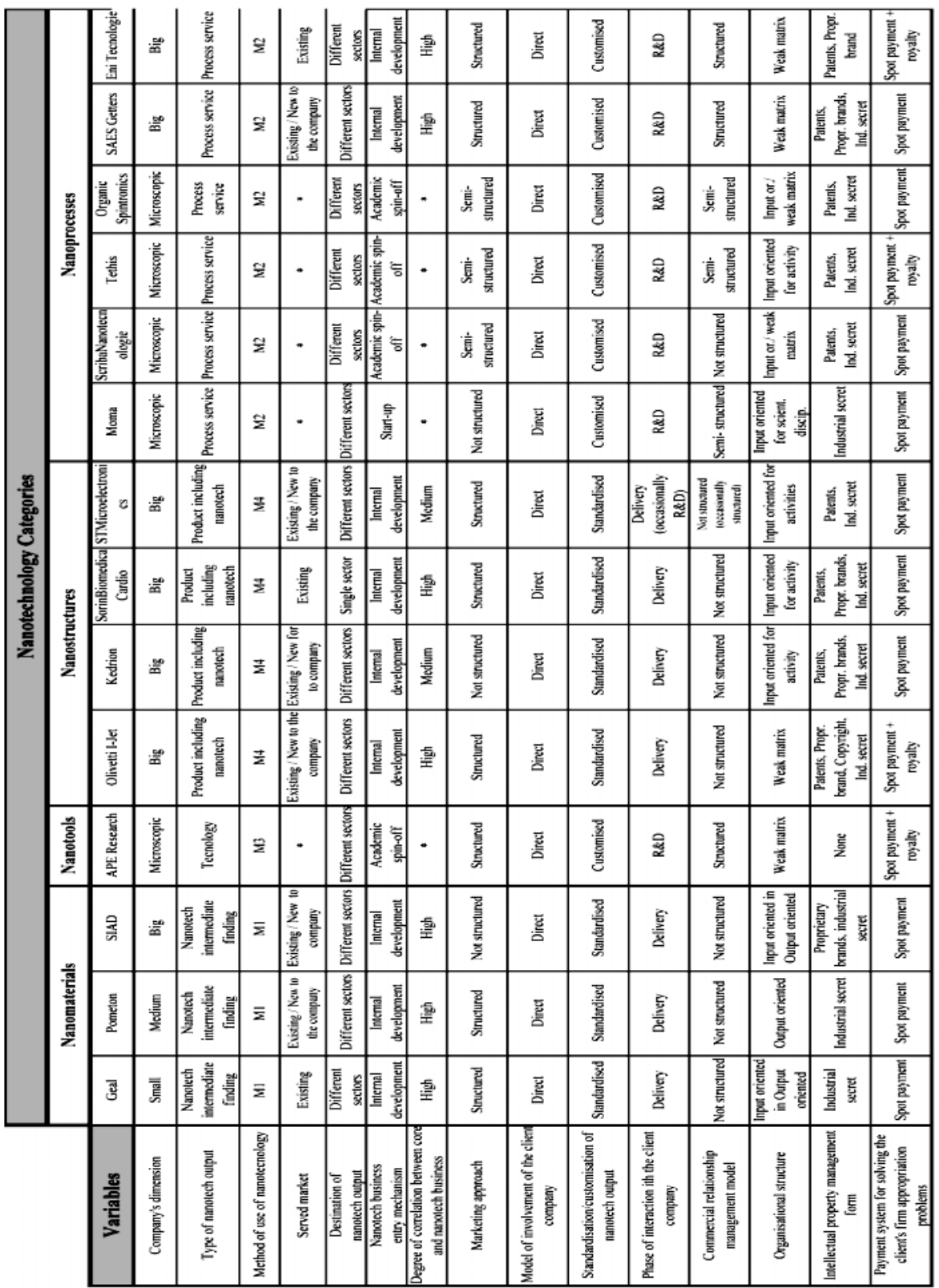

Table 4. The empirical evidence emerged from the intensive analysis (the symbol ‘` means that for start-ups and academic spin-offs the value of the variable is senseless). 
M4. the method adopted by those nanotech companies internally developing, acquiring or licensing in from other companies nanotechnological processes, tools, or intermediate findings to be used for innovating their processes or products; it is typical of companies operating in the nanotechnology category of nanostructures.

- All companies use nanotechnologies to serve an existing market, even if in some cases the nanotech output opens a new market. This shows that the Italian nanotech companies are more inclined to exploit nanotechnology in order to strengthen the position in their core business rather than to diversify into different businesses. This is proved by the basically high degree of correlation between the core and the nanotech business.

- The firms, with the only exception of Sorin Biomedica Cardio, address their nanotech output to companies belonging to different industrial sectors. Nanotechnology, in fact, has a great pervasiveness, that brings companies offering an output in this scientific domain to direct their offer to firms operating in various sectors of activities; this is necessary if they mean: (i) to fully exploit the potentiality of the technical knowledge they possess; (ii) to make economically bearable the huge investments in nanotech applications. In the case of Sorin Biomedica Cardio, the choice to direct the offer exclusively to the biomedical sector is dictated by the corporate strategy of Sorin Group, which is uniquely focused on the sector of biomedicine, and the peculiarity of its nanotech applications.

- All companies have entered the nanotech business through the mechanism of internal development (even the start-ups and spin-offs have internally developed their knowhow on nanotechnologies). This unequivocal choice can be explained in the light of three main factors: (i) the high degree of correlation between the core and the nanotech business, which has pushed the firms to internally develop the nanotech competencies; (ii) the embryonic stage of the Italian nanotech market, which has made difficult to find external holders of nanotech competencies; (iii) the limited experience of Italy in corporate venturing activities, that has hindered the adoption of new business entry mechanisms different from internal development (e.g. venture capital investments).

- Almost all companies adopt a structured marketing approach based upon the dispatch of information packs to potential clients, the participation to professional fairs and the use of the website as a window on the firm's projects and services. The contact of new potential clients seems therefore to be a critical aspect for the analysed firms. The only cases of non-structured marketing approach are that of: (i) Kedrion and SIAD, since they are still far from the phase of commercialisation of nanotech applications (both the companies have in fact revealed that will likely adopt a structured marketing approach once arrived in the commercialisation phase); (ii) Moma (in this case, the extremely small dimension (four employees) of the firm prevents it from possessing the financial and human resources needed for undertaking structured marketing initiatives);

- All companies adopt a direct model of involvement of the client company, i.e. interact personally with the client firm's reference people. The high complexity of nanotechnology and the current scant knowledge of its applications by client firms make personal contact very important with the client and prevent nanotech players from adopting indirect models of client's involvement (e.g. online selling).

- Considering the other three dimensions of the sale management model, i.e. the commercial relationship management approach, the phase of interaction with the client company and the degree of standardization of the provided service, it could be stated that two alternative models seem to be applied by Italian nanotech firms in the management of the service sale. They are: 
- Customized model, characterized by: (i) customized output; (ii) interaction with the client companies since the earliest phase of development; (iii) structured commercial relationship management model.

- Standardized model, characterized by: (i) standardized output; (ii) interaction with the client companies only in the phase of output delivery; (iii) not structured commercial relationship management model.

- No specially interesting findings seem to appear when the organisational structure of the companies, the intellectual property management model, and the strategies used for solving the appropriation problems are considered.

\subsection{Emerging business models among italian nanotech companies}

The collected empirical evidence suggests the existence of correlations between: (i) the nanotechnology category in which the companies work; (ii) their dimension; (iii) the adopted sale management model. It seems therefore that four main types of business model can be identified among the Italian nanotech players (Figure 2).

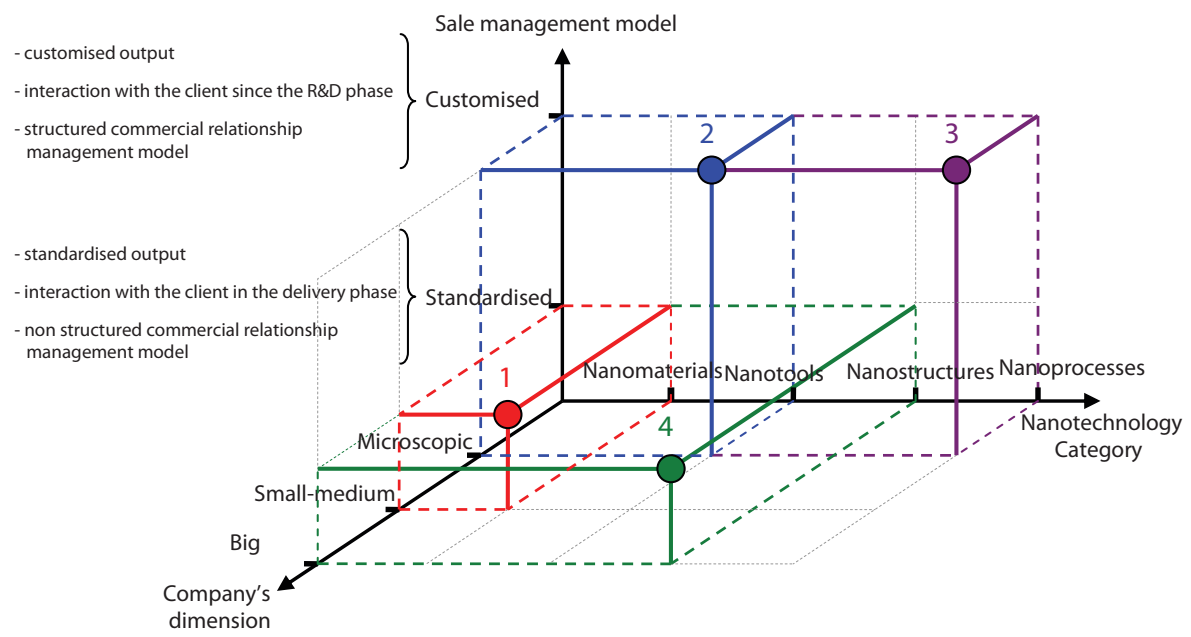

Fig. 2. The emerging business models among Italian nanotech companies.

1. The configuration generally adopted by small and medium sized enterprises operating in the nanotechnology category of nanomaterials with a standardised sale management model (Geal, Pometon). They are companies offering a service of "Work In Progress (WIP) innovation". The adoption of a standardised sale management model can be partially understood if it is considered that a "WIP innovation" is an intermediate finding that needs to be further developed by the client company and included in its final products. In order to allow that this intermediate finding is incorporated into the widest range of finished products, it must have general properties. The case of SIAD might seem an exception since it operates in the category of nanomaterials and adopts a standardised sale management model, but is a big company; anyway, the part that within the company is dedicated to the business of nanomaterials has a small dimension.

2. The configuration adopted by microscopic companies operating in the category of nanotools with a customised sale management model (A.P.E. Research). They are companies offering a service of "Technologies to develop technology" that is used by the 
client firm for supporting its innovation processes. In order to understand why "technologies to develop technology" are sold according to a customized model, it is necessary to remember that nanotechnology has a highly interdisciplinary feature. Therefore, a nanotech-based tool (e.g. a Scanning Probe Microscope) can be useful in supporting the client firm's innovative activities only if it fits its particular requirements.

3. The typical configuration of microscopic firms operating in the category of nanoprocesses with a customised sale management model (Moma, Organic Spintronics, Scriba Nanotecnologie, Tethis). They are companies providing a service of "Process activity". The adoption of a customised sale management model in this case is reasonable if it is considered that "process activity" is a cluster of services that is necessarily highly customized; the actual necessities of the innovator, in fact, strictly influence the type of activities to be undertaken by the "outsourcer" nanotech company. The cases of SAES Getters and EniTecnologie might seem exceptions since they work in the category of nanoprocesses and adopt a customised sale management model, but have a big dimension; however, if the activities undertaken are carefully considered, it clearly emerges that the part that within the companies is dedicated to the nanotech business has a microscopic dimension.

4. The configuration adopted by big companies working in the category of nanostructures with a standardised sale management model (Olivetti I-Jet, Kedrion, Sorin Biomedica Cardio, STMicroelectronics). They are companies that apply nanotechnologies, internally developed or acquired from other companies, for innovating their products. They are therefore companies that sell finished products including nanotechnologies. The only firms operating in the category of nanostructures are big ones, and this can be partially explained by considering that nanostructures are complex systems (e.g. molecular logic circuits, organic LEDs) that require, in order to be fully developed and sold to the final customer, huge investments that can be afforded uniquely by big companies; a small company, in fact, seldom possesses the financial resources needed in order to finish the manufacture of a nanostructure to be sold to the client. Furthermore, the adoption of a customised sale management model can be explained in the light of the fact that nanostructures are finished systems capable of autonomously functioning that the customer can use without any need for modification and customisation.

The classification of the business models of the Italian nanotech companies in the four aforementioned configurations seems to be a viable instrument for further analysing nanotech companies from a managerial perspective. It has in fact proved to be capable of explaining significant differences among the players in terms of: (i) nanotechnology category where they work; (ii) dimension; (iii) sale management model.

Unluckily, at the moment, the number of nanotech companies in Italy is very low and it will be necessary to wait for the development and proliferation of new companies in order to verify if the identified business models represent a common trend of development in particular clusters of nanotech firms.

\section{Conclusions and implications}

Interest towards nanotechnology has largely grown in the last 7 to 8 years, and this scientific field has proved to be particularly promising for the development of an emerging and rapidly-growing market for nanotech applications. The paper offers a picture of the overall Italian market for nanotech applications and provides an insight into the management and organisation of the players operating in such a market.

In order to achieve this purpose, an empirical study was conducted. It was divided into two 
distinct parts: (i) an extensive analysis, aimed at identifying the main players of the Italian market for nanotech applications and collecting some general information useful for understanding the market as a whole; and (ii) an intensive analysis, aimed at investigating the management and organisational practices adopted by Italian nanotech players. The collected empirical evidence has allowed the identification of some emerging business models adopted by Italian nanotech companies. An explanation of the determinants of these business configurations in light of the specific characteristics of the different players and the nanotechnology categories in which they operate has then been provided.

The results of the empirical study have significant implications both for academics and practitioners: First, it is believed that the present research can benefit researchers interested in the study of the nanotech market and, in general, the high-tech industries. They are encouraged to adopt the research methodology suggested in the paper in order to compare the major findings in the Italian landscape with the case of other countries and high-tech industries. This would help to extend the present research's results and advance the extant knowledge about the development trends and the emerging business models within growing high-tech industries.

Second, the paper suits as a background policy document for policy makers and investors in Italy. The high-tech industries are being paid increasing attention in the design of public policies (U.S. Government, 2006, 2003), and particularly the nanotech industry is considered critical for favouring the development of advanced economies (European Commission, 2004c). In this respect, the paper's achievements are useful since they suggest how to build a system of supporting initiatives that fits with the current evolution and characteristics of the Italian nanotech industry; these initiatives, in fact, are likely to be far more effective, in a specific stage of the industry's life cycle, if they aim at stimulating the diffusion of those firms that adopt the types of business models which are contextually capable of generating and delivering the highest value added.

Third, the paper provides corporate executives with useful insights into the role played by nanotechnology within a business context and the way the nanotech companies are currently managing and organising their business activity. In order to define the optimal business model for their companies, the executives of firms aimed at commercialising nanotech applications should first consider the current characteristics of the nanotech market and its stage of development, and then adapt the role they mean to play in the market to the figure that is likely to be precursory of the highest value.

The empirical study has made a step further in the investigation of the growing market for nanotech applications, offering some empirical evidence about the business models applied by companies operating in the nanotechnology domain. An interesting future direction of research consists in expanding the analysis here presented to other countries and high-tech industries (e.g. the biotech sector). This would give the opportunity to understand whether the major findings described in this paper prove valuable in other contexts and, if not, what the contextual variables (country-specific and/or industry-specific) might be that would explain the emerging differences. The ongoing research project means to shed light on this topic.

\section{References}

Caravita, G. (2004a) Nanotech, arriva la mappa italiana. @lfa Il Sole-24 Ore, 15 July. Caravita, G. (2004b) Il nanotech cala un tris d'assi. @lfa Il Sole-24 Ore, 2 December.

Chesbrough, H. \& Rosenbloom, R. S. (2002) The role of the business model in capturing value from innovation: evidence from Xerox Corporation's technology spin-off companies. Industrial and Corporate Change, 11, 3, 529-555. 
Chiesa, V. \& De Massis, A. (2006) La nanoindustria: analisi dei principali player italiani nelle nanotecnologie. Roma: Aracne Editrice.

Chiesa, V., De Massis, A. \& Frattini, F. (2005a) Emerging business models in TSS: the case of nanotechnology in Italy. In Khalil T. (eds.) Productivity Enhancement for Social Advance: The Role of Management of Technology - IAMOT 14th International Conference on Management of Technology Proceedings, Vienna, Austria, 22-26 May.

Chiesa, V., Frattini, F., Lazzarotti, V. \& Manzini, R. (2005b) Managing and organizing technical and scientific service companies: a conceptual framework and an empirical study. In Khalil T. (eds.) Productivity Enhancement for Social Advance: The Role of Management of Technology - IAMOT 14th International Conference on Management of Technology Proceedings, Vienna, Austria, 22-26 May.

Debackere, K. (1999) Technologies to develop technology. Antwerp, Belgium: MAKLU Publishers.

Eisenhardt, K.M. (1989) Building theories from case study research. Academy of Management Review, 14, 4, 532-550.

European Commission (2004a) Nanotechnology, innovation for tomorrow's world, April, available at http:/ / www.cordis.lu/nanotechnology/src/pressroom.htm.

European Commission (2004b) Vision 2020, Nanoelectronics at the center of change, June, available at http:/ / www.cordis.lu/nanotechnology/src/pressroom.htm.

European Commission (2004c) Communication from the Commission: Towards a European strategy for nanotechnology. Bruxells, Belgium, May.

Hellström, T. \& Sjölander, S. (2005) Entrepreneurial learning \& academic spin-offs - Project report to Nordic Innovation Centre. Göteborg: Norden Nordic Innovation Centre.

Hewson, C., Yule, P., Laurent, D. \& Vogel, C. (2003) Internet Research Methods. London: Sage Publications.

Nanotech/IT. (2004) Nanotech IT Newsletter, 1, April.

Patton, M.Q. (1987) How to use qualitative methods in evaluation. Thousand Oaks, California, US: Sage Publications.

Shafer, S.M., Smith, H.J. \& Linder, J.C. (2005) The power of business models, Business Horizons, 48, 199-207.

U.S. Government (2003) 21st Century Nanotechnology Research and Development Act, December, available at http://www.nsf.gov/crssprgm/nano/activities/congress.doc.

U.S. Government (2006) American Competitiveness Initiative. Leading the World in the Innovation, Domestic Policy Council Office of Science and Technology Policy, February.

Yin, R. K. (2003) Case Study Research: Design and Methods. Thousand Oaks, California, US: Sage Publications.

The main websites consulted for the elaboration of the paper are ${ }^{1}$ :

www.luxresearchinc.com, 2004.

www.nanobusiness.org, 2000.

www.nanoinvestors.com, 2004.

www.nanoinvestornews.com, 2004.

www.investinitaly.com, 2004.

www.nanotec.it, 2004.

www.nanovip.com, 2004.

${ }^{1}$ The list of websites includes only the ones cited in the text. The elaboration of the paper, in fact, required the consultation of a great number of websites since part of the empirical study (the extensive analysis) was mainly based on the web. 


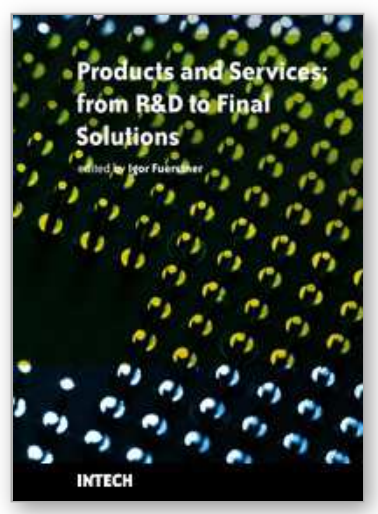

\author{
Products and Services; from R\&D to Final Solutions \\ Edited by Igor Fuerstner
}

ISBN 978-953-307-211-1

Hard cover, 422 pages

Publisher Sciyo

Published online 02, November, 2010

Published in print edition November, 2010

Todayâ€ $\mathrm{TM}^{\mathrm{TM}}$ global economy offers more opportunities, but is also more complex and competitive than ever before. This fact leads to a wide range of research activity in different fields of interest, especially in the socalled high-tech sectors. This book is a result of widespread research and development activity from many researchers worldwide, covering the aspects of development activities in general, as well as various aspects of the practical application of knowledge.

\title{
How to reference
}

In order to correctly reference this scholarly work, feel free to copy and paste the following:

Lucio Cassia and Alfredo De Massis (2010). The Market for Nanotechnology Applications and its Managerial Implications: an Empirical Investigation in the Italian Landscape, Products and Services; from R\&D to Final Solutions, Igor Fuerstner (Ed.), ISBN: 978-953-307-211-1, InTech, Available from:

http://www.intechopen.com/books/products-and-services--from-r-d-to-final-solutions/the-market-fornanotechnology-applications-and-its-managerial-implications-an-empirical-investigatio

\section{INTECH}

open science | open minds

\section{InTech Europe}

University Campus STeP Ri

Slavka Krautzeka 83/A

51000 Rijeka, Croatia

Phone: +385 (51) 770447

Fax: +385 (51) 686166

www.intechopen.com

\section{InTech China}

Unit 405, Office Block, Hotel Equatorial Shanghai

No.65, Yan An Road (West), Shanghai, 200040, China

中国上海市延安西路65号上海国际贵都大饭店办公楼 405 单元

Phone: +86-21-62489820

Fax: $+86-21-62489821$ 
(C) 2010 The Author(s). Licensee IntechOpen. This chapter is distributed under the terms of the Creative Commons Attribution-NonCommercialShareAlike-3.0 License, which permits use, distribution and reproduction for non-commercial purposes, provided the original is properly cited and derivative works building on this content are distributed under the same license. 